\title{
RECORTES LITERÁRIO E BIOGRÁFICO DE MONTEIRO LOBATO NA DEFESA DA EUGENIA E DO FASCISMO RACIAL
}

\author{
REGINA MARIA DE SOUZA \\ https://orcid.org/0000-0002-4880-4361 \\ Universidade Estadual de Campinas \\ MORENA DOLORES PATRIOTA DA SILVA \\ https://orcid.org/0000-0002-9891-7938 \\ Instituto Federal do Paraná - Campus Londrina \\ Universidade Estadual de Campinas

\section{CRISTIANE MARIA DA SILVA} \\ https://orcid.org/0000-0001-5468-6632 \\ Universidade Estadual de Campinas
}

RESUMO O presente trabalho tem como objetivo discutir as bases do processo eugênico contra a raça negra, defendidas na obra $O$ presidente negro, de Monteiro Lobato (primeira edição em 1926). A análise da obra realizou-se a partir de defensores da eugenia, dentre eles Renato Kehl, e de trabalhos acadêmicos atuais que demonstram o tributo deixado pela eugenia no olhar e nas ações voltados à população negra. A conclusão é de que o projeto eugênico, proposto por Francis Galton em 1883, que chegou ao Brasil no início do século XX, mantém-se presente, escancarado no significativo número de negros assassinados no Brasil, em relação ao de brancos; escamoteado em produções acadêmicas e livros didáticos que ainda reverberam e exaltam as ideias de Lobato; mascarado na formação universitária de pesquisadores, no Brasil e no exterior. Formação fragmentada e fragmentária que, sem um olhar histórico diacrônico, acaba por alimentar, em gerações futuras, a crença na possibilidade de uma organização social e instituições sem conflitos, propostas e governadas, em sua maioria, por brancos que ouvem as diferenças, mas não transformam essa audição em escuta que possa romper a lógica de branqueamento e de controle sobre elas.

Palavras-chave: Eugenia. Racismo. Miscigenação. Escamoteamento. Educação. 


\section{MONTEIRO LOBATO IN DEFENSE OF EUGENICS AND RACIAL FASCISM}

The present work aims to discuss the eugenic bases against the black race defended in the work The Black President de Monteiro Lobato (first edition of 1926). The analysis of the work was carried out from advocates of eugenics, among them Renato Kehl, and current academic works that demonstrate the tribute left by eugenics in the eye and actions aimed at the black population. The conclusion is that the eugenics project, proposed by Francis Galton in 1883, which arrived in Brazil at the beginning of the 20th century, is still present, open to the significant murder of blacks in Brazil in relation to whites, hidden in academic productions and textbooks that keeps reverberating and exalting Lobato's ideas, masked in the university education of researchers, in Brazil and abroad. A fragmented and fragmentary formation that, without a diachronic historical view, ends up feeding, in future generations, the belief in the possibility of a social organization and institutions without conflicts, proposals and governed, mostly, by whites who listen to the differences, but without transforming this hearing into listening that can break the logic of bleaching and control over them.

Keywords: Eugenics. Racism. Miscegenation. Concealment. Fadingness. Education.

\section{RESUMEN RECORTES LITERARIOS Y BIOGRÁFICOS DEL}

\section{MONTEIRO LOBATO EN DEFENSA DE LA EUGENESIA Y \\ EL FASCISMO RACIAL}

El presente trabajo tiene como objetivo discutir las bases eugenésicas contra la raza negra defendida en la obra El Presidente Negro de Monteiro Lobato (primera edición de 1926). El análisis del trabajo se realizó desde los defensores de la eugenesia, entre ellos Renato Kehl, y los trabajos académicos actuales que demuestran el tributo que la eugenesia deja en el mirar y en las acciones dirigidas a la población negra. La conclusión es que el proyecto eugenésico, propuesto por Francis Galton en 1883, que llegó a Brasil a principios del siglo $\mathrm{XX}$, sigue presente, abierto al significativo asesinato de negros en Brasil en relación con los blancos, escondidos en producciones académicas y libros de texto que siguen reverberando y exaltando las ideas de Lobato, enmascaradas en la educación universitaria de los investigadores, en Brasil y en el exterior. Una formación fragmentada y fragmentaria que, sin una visión histórica diacrónica, 
acaba alimentando, en las generaciones futuras, la creencia en la posibilidad de una organización social e instituciones sin conflictos, propuestas y gobernadas, en su mayoría, por blancos que oyen las diferencias, pero sin transformar el oír en una escucha que pueda romper la lógica del blanqueo y del control sobre ellas.

Palabras Clave: Eugenesia. Racismo. Mestizaje. Escamoteamento. Educación.

\section{Introdução}

Racismo nasce da relação de poder. De poder ter influência ou gerência sobre as vidas de quem é considerado inferior. (GONÇALVES, 2011, [s.p.])

A inspiração para esta pesquisa partiu do reconhecimento de uma das formas mais visíveis de eliminação da presença negra: o índice de assassinatos cometidos contra os negros. Esse fato é veiculado pela mídia e bem conhecido em nosso país, sem que, todavia, sejam tomadas medidas efetivas pelo Estado para mudar esse cenário. 0 assassinato da ativista Marielle Franco, em 14 de março de 2018, põe a nu a realidade a ser transformada: a morte brutal e cujas investigações apontam para uma estrutura criminosa, que denota o ódio a uma mulher negra, homossexual, oriunda da favela, que estudou e era vereadora do Rio de Janeiro, militante dos direitos humanos com ênfase nos direitos da mulher e dos negros e que, conforme relatado pela jornalista Renata Souza no site El País (2018), denunciava o "grau de letalidade da política de segurança pública" que teria como alvo "[...] jovens negros da favela e periferia". Outra situação trágica ocorreu em 07 de abril de 2019, no Rio de Janeiro, em que Edvaldo, um músico de 51 anos, negro, que ia para uma festa com sua família na zona oeste da cidade, teve seu carro alvejado por mais de 80 tiros, segundo agências de notícias. Todavia, laudo oficial divulgado em maio aponta que foram disparados mais de 200 tiros contra o carro da família. Tratava-se de uma ação do Exército na ocasião, mas que denota como a política de segurança pública está voltada para decisões em que a cor de pele é fator determinante para ações policiais de extermínio (LANG, 2019; MENEZES, 2017). Marielle e Edvaldo tornam-se, assim, não mais corpos sem vida, mas vidas sociais que exigem ser transformadas para garantir ao outro a existência.

Para demonstrar o atual genocídio de jovens negros, elegemos duas fontes distintas e recentes com levantamentos sobre o processo de eliminação dos negros no Brasil, descritas a seguir.

Em 18 de novembro de 2017 foi publicada uma reportagem de Menezes no Jornal Nacional, disponivel no site G1, que afirma que $71 \%$ dos homicídios do País têm negros como vítimas. É citada uma pesquisa do Fórum Brasileiro de Segurança Pública de 2017, segundo a qual "o levantamento mostrou que o abismo entre brancos e negros aumentou na última década. Entre os mortos nos homicídios registrados de 2005 a 2015, o número de brancos caiu 12\%. E o de negros, aumentou 18\%" (MENEZES, 2017).

É possível verificar, no Atlas da Violência de 2019, que as porcentagens apresentadas por Menezes no site do G1 (2017) não são exatamente as mesmas, mas bem próximas: talvez por ter sido levantamento parcial, à época da publicação da notícia (novembro de 2017). Os dados do Atlas, consolidados e oficiais, refe- 
rem-se ao ano todo de 2017, mas foram publicados em 2019. O que se nota é um aumento de $4,5 \%$ nos homicídios de negros, entre os dados parciais de novembro e a consolidação da pesquisa em 2017.

No Atlas da Violência 2019, verificamos a continuidade do processo de aprofundamento da desigualdade racial nos indicadores de violência letal no Brasil, já apontado em outras edições. Em 2017, 75,5\% das vítimas de homicídios foram indivíduos negros (definidos aqui como a soma de indivíduos pretos ou pardos, segundo a classificação do IBGE, utilizada também pelo SIM), sendo que a taxa de homicídios por 100 mil negros foi de 43,1 , ao passo que a taxa de não negros (brancos, amarelos e indígenas) foi de 16,0 . Ou seja, proporcionalmente às respectivas populações, para cada indivíduo não negro que sofreu homicídio em 2017, aproximadamente, 2,7 negros foram mortos. (FÓRUM BRASILEIRO DE SEGURANÇA PÚBLICA, 2019, p. 49)

Outra reportagem, essa no site do Jornal $O$ Estado de São Paulo, datada de 5 de junho de 2018, traz a conclusão de um grupo de pesquisadores, coordenados pelo economista Daniel Cerqueira, que reitera o divulgado pelo Atlas:

A conclusão é que a desigualdade racial no Brasil se expressa de modo cristalino no que se refere à violência letal e às políticas de segurança. Os negros, especialmente os homens jovens negros, são o perfil mais frequente do homicídio no Brasil, sendo muito mais vulneráveis à violência do que os jovens não negros", acrescentaram os estudiosos. Eles pedem que os dados sejam usados para elaboração de eficientes políticas de prevenção da violência, "desenhadas e focalizadas, garantindo o efetivo direito à vida e à segurança da população negra no Brasil. (CARVALHO, 2018, [s.p.])

Embora essa eliminação não tenha sido planejada, ou defendida explicitamente, como política de governo, algumas ações institucionais acabam por expor o preconceito da população, levantando a preocupação de que ações como essas possam vir a ser ou naturalizadas ou institucionalizadas. Consideremos aqui o ocorrido em 2013 na cidade de Campinas, São Paulo, quando um capitão da polícia militar elaborou um documento com orientações a policiais para realização de abordagem em determinada região da cidade focada em "indivíduos de cor parda e negra" (G1 CAMPINAS; TV GLOBO, 2013).

Este tipo de orientação, notadamente racista, é flagrante (e atual) na obra O Presidente negro ou o choque das raças, de Monteiro Lobato.

Vale ressaltar que utilizamos ao longo do artigo o termo "genocídio", como proposto por Abdias do Nascimento (1978, p. 14), que assume a definição apresentada no dicionário Webster de Língua Inglesa:

[...] uso de medidas deliberadas e sistemáticas (como morte, injúria corporal e mental, impossíveis condições de vida, prevenção de nascimento), calculadas para a exterminação de um grupo racial, político ou cultural, ou para destruir a língua, a religião ou a cultura de um grupo.

Neste sentido compreende-se que não somente os massacres violentos que acabam culminando com a morte de várias pessoas de uma determinada identidade cultural, étnica e/ou racial caracterizam genocídio, mas todo ato deliberado e sistemático, como apontado acima, que visa à aniquilação de um grupo, mesmo que de modo gradual. As ações militares que têm como objeto a população negra caracterizam, portanto, uma política genocida.

Tendo em vista o tema aqui escolhido - o genocídio (por extermínio ou gradual eliminação) da população negra -, o presente trabalho discutirá as ações eugênicas voltadas contra a raça negra explicitamente defendidas na obra $O$ presidente negro, escrita por Monteiro Lobato, e a forma como elas se mantêm na atualidade. 
Neste artigo, em um primeiro momento, apresentaremos um resumo da obra de Monteiro Lobato, considerando o fato de sua pouca circulação em nossa época.

Em seguida, retornaremos ao que foi o movimento eugênico e sua base epistemológica, faremos um diálogo com a obra de Monteiro Lobato e nos itens seguintes demonstraremos como o processo eugênico se mantém nos dias atuais. Nesse sentido, apontaremos o tributo histórico deixado pelo Estado, pelo qual ainda somos afetados; tributo esse claramente expresso na Constituição de 1934, que fez da Eugenia uma política de Estado.

\section{Monteiro Lobato e o Presidente}

\section{negro}

Meu romance não encontra editor. [...]. Achamno ofensivo à dignidade americana, visto admitir que depois de tantos séculos de progresso moral possa este povo, coletivamente, cometer a sangue frio o belo crime que sugeri. Errei vindo cá [EUA] tão verde. Devia ter vindo no tempo em que eles linchavam os negros. (LOBATO apud GONÇALVES, 2011, [s.p.])

Nascido José Bento Renato Monteiro Lobato (1882-1948) na cidade de Taubaté, interior de São Paulo, seis anos antes da abolição da escravatura no Brasil, Monteiro Lobato é reconhecido nacionalmente como autor literário, em especial por suas produções de literatura infantojuvenil. Entusiasta da eugenia, foi membro da Sociedade Eugênica de São Paulo (STEPAN, 2004) e correspondeu-se por cartas com outros eugenistas, como Renato Kehl e Arthur Neiva, defendendo e exaltando os ideais eugênicos (NIGRI, 2011).

O único romance adulto escrito por Monteiro Lobato foi $O$ presidente negro ou $O$ choque das raças, publicado em 1926. Também chamado de Guerra das raças (LOBATO, 1948), o livro inicia-se contando a sina de um corretor, Ayrton Lobo, que trabalha para uma empresa da qual retira o seu sustento. Em uma de suas viagens a trabalho com o carro, sofre um acidente grave e perde a consciência. Quando acorda, se vê em um castelo confortável, localizado em suntuosa propriedade rural nas proximidades de Friburgo, muito conhecida pelos habitantes da cidade, pelo dificil acesso a ela, pela reclusão social de seu proprietário, professor Benson, que tinha, sem que ninguém entendesse, êxito total em suas aplicações financeiras, em especial, no câmbio. Pois bem, é nesse contexto que desperta o patético corretor.

Ayrton se mantém na casa, em companhia de Miss Jane, filha de Benson, que o trata com especial atenção. Ao longo da história, ambos se apaixonam, ao mesmo tempo que Jane inicia a educação de Ayrton para que possa ter acesso a todos os conhecimentos e descobertas "científicas" do seu pai, inclusive, àquela que lhe permite obter sucessos em investimentos de câmbio.

Desde o início, o leitor se pergunta o motivo pelo qual uma mulher tão brilhante e bonita se interessaria por um sujeito como Ayrton. Esta compreensão é intuída facilmente pelo leitor, aos poucos, e pelo próprio Ayrton, narrador da história. Professor Benson já era idoso, a morte se aproximava. Deveria haver um sucessor, um discípulo fiel, obediente e que admirasse a filha e o projeto de seu pai de modo servil. Ayrton tinha este perfil.

Jane, em dado momento, solicita que tudo que aprendesse, Ayrton descrevesse detalhadamente em uma obra, para que as futuras gerações pudessem ter acesso às contribuições de seu pai. Para a maioria dos leitores, a obra seria classificada como ficção e, segundo Jane, faria grande sucesso. Em futuro distante, os leitores iriam admirar o trabalho visionário de seu pai: "um dia a humanidade se assanhará diante das previsões do escritor [Ayrton], e os cientistas quebrarão a cabeça no estudo de um caso, único no mundo, de profecia integral 
e rigorosa até nos mínimos detalhes" (LOBATO, 1948, p. 183). As previsões foram possiveis pela invenção, por Benson, de uma máquina que antecipava acontecimentos futuros, a qual chamou de porviroscópio, o que explica sua "sorte" em suas aplicações financeiras.

Com o porviroscópio, soube que em 2228, ocorreria uma eleição presidencial nos Estados Unidos, extremamente disputada e inusitada, pois, entre os candidatos, estaria Jim Roy, um negro com grande apoio de seus pares; além dele, o presidente em exercício, Kerlog, branco, estava em franca campanha para sua reeleição. Uma terceira personagem entra nessa arena de disputa, Miss Astor, candidata branca feminista.

As mulheres defenderiam um discurso de base eugenista em relação também aos homens, com a tese de que provinham de uma linhagem evolucionista inferior, ou seja, seriam parentes dos primatas, da linhagem dos gorilas; já, elas, as mulheres, teriam descendido dos sabinos, espécie de anfíbio ágil, de inteligência aguda, com grande perspicácia (LOBATO, 1948).

Nas discussões entre os candidatos brancos com suas bases, os homens decidiriam solicitar o apoio das comunidades negras americanas, visto que, segundo eles, seriam mais facilmente controladas do que as mulheres brancas. À época, estaria em vigor a Lei Owen, que valorizava a pureza da raça branca, sem mesclas e sem quaisquer sujeitos com "anormalidades" (ou taras) ou "desgraçados por defeito mental" (LOBATO, 1948, p. 212). Segundo Jane, em 2228, os primeiros alvos da Lei de Owen seriam as pessoas com deficiência ou com doenças mentais; os criminosos; os corruptores; as prostitutas, dentre outros:

Esses foram impedidos de se reproduzirem pela Lei Owen, fruto das grandes ideias pregadas por Walter Owen. Walter Owen foi o verdadeiro remodelador da raça branca na América. [...] A lei
Owen, como era chamado esse Código da Raça, promoveu a esterilização dos tarados, dos malformados mentais, de todos os indivíduos em suma capazes de prejudicar com má progenie o futuro da espécie. [...] Desapareceram os peludos - os surdos-mudos, os aleijados, os loucos, os morféticos, os histéricos, os criminosos natos, os fanáticos, os gramáticos, os místicos, os retóricos, os vigaristas, os corruptores de donzelas, as prostitutas, a legião inteira de malformados no físico e no moral, causadores de todas as perturbações da sociedade humana. [...] Crescer para a América não equivalia mais a avultar ás tontas em numero, como hoje, e sim a elevar o índice mental e físico dos seus habitantes. (LOBATO, 1948, p. 212)

Um fato interessante a ser destacado era a relação numérica dos eleitores. Os brancos, homens e mulheres, contariam com 51 milhões de votos cada. Homens e mulheres negros somariam 54 milhões. Portanto, as partes brancas das candidaturas - Kerlog e Astor -voltarse-iam a cooptar o candidato negro, Jim Roy.

Em reunião com Kerlog, com vista a uma possivel coligação, Jim Roy insistiria na atenuação da lei de Owen, que, em ano anterior, teria incluído um item que se referia aos negros, com o objetivo de diminuir o índice de procriação da raça. Roy queria o contrário, ou seja, a livre procriação negra, o que, para ele, acabaria resultando na divisão do território americano em dois: um para a raça negra (o Sul) e outro para a branca (o Norte).

Por coisa nenhuma queriam os brancos transigir no terreno restritivo da Lei Owen - seria um suicídio. Mas a situação metera a politica naquele buraco: ou ceder ás exigencias de Jim Roy ou assistir á vitoria das mamiferas rebeldes. Quando o presidente [Kerlog] terminou a sua exposição calaram-se os ministros por algum tempo, de queixo preso. Qualquer das hipoteses não agradava ao macho branco. Mas como a sabedoria em pragmatica consiste em acudir primeiro ao perigo mais próximo, foi acordado ceder ás exigencias do lider negro. (LOBATO, 1948, p. 228) 
Da mesma forma, Roy seria convidado para se reunir com Miss Astor, fato que rapidamente chegaria ao partido de Kerlog. 0 argumento utilizado por ela para ter apoio de Roy seria o seguinte:

O choque das raças vai dar-se, disse ela. Precipita-se. Será um conflito tremendo, mas só no caso de estar no poder o homem branco, criador do odio ao negro. Tudo mudará, se em vez desse implacável inimigo comum estivermos no poder nós mulheres. (LOBATO, 1948, p. 230, grifo nosso)

Astor continuaria defendendo a tese de que negros estavam sob o jugo branco há centenas de anos, enquanto as mulheres, desde sempre. Portanto, os dois grupos sofreriam as ações do mesmo "inimigo em comum" (LOBATO, 1948, p. 230).

Jim Roy decidiria conclamar a união de negros e negras e, assim, sairia vitorioso na eleição presidencial. Com esse resultado, as mulheres retornariam, de imediato, à submissão aos homens brancos.

Logo depois do resultado, na Convenção da Raça Branca (só de homens), decidir-se-ia produzir um alisante de cabelos com um novo componente químico (raios Ômega) que tornaria a população negra estéril. O lançamento do produto seria eficientemente realizado por propagandas e calculado trabalho de marketing. 0 alisante seria comprado e utilizado em massa pelos negros. No dia anterior à posse, Kerlog iria à casa de Jim Roy, para avisar que trazia "na boca a palavra que mata" (LOBATO, 1948, p.314) e, em seguida, contaria a ele o feito e seu efeito: o fim da raça negra realizado pelas próprias mãos dos negros.

Nem Shakespeare descreveria o aspecto do lider negro no momento em que a palavra assassina the despedaçou o coração. [...] Breves crispações de musculos passearam-lhe pelas faces. Dobrou o corpo sobre a secretária.
O lider branco aproximou-se daquela massa de titã extinto, afagou-lhe a pobre cabeça omegada e disse com voz rompida de soluços: - "Perdoa-me, Jim...." (LOBATO, 1948, p. 317)

Meses depois do aparecimento dos raios Omega o indice da natalidade negra caiu de chofre. Março, precisamente o nono mês a datar da abertura dos primeiros postos desencarapinhantes, acusava uma queda de $30 \%$. Esta porcentagem subiu ao dobro em abril e chegou a $97 \%$ em maio. Em junho as estatisticas só registravam 122 negrinhos novos. (LOBATO, 1948, p. 322)

\section{Eugenia: o que é}

Anima-me a crença de ter scripto um livro util. Tenho como certo que muitos leitores participarão da minha fé na doutrina de Galton e as minhas esperanças num futuro cada vez mais promissor para a humanidade. Para esse fim, já observei, é indispensável o progresso individual, de modo que cada um envide esforços para o progresso collectivo. (KEHL, 1923, p. 3, grifo nosso)

"Eugenia", termo cunhado por Francis Galton (1822-1911), primo de Charles Darwin, foi um dos efeitos do darwinismo social, corrente de pensamento que se organizou durante o período de Pós-Revolução Industrial na Inglaterra, marcado pelo vertiginoso crescimento urbano, jornadas exaustivas com péssimas condições de higiene no trabalho, pobreza extrema, doenças, criminalidade e aumento de vícios, destacando-se o abuso de álcool (DIWAN, 2007).

Nesse cenário, a população resistiu e passou a reivindicar melhores condições de vida, enquanto a burguesia, com a legitimação de pesquisadores de renome, como Galton, desenvolvia teorias que justificavam as mazelas sociais, culpabilizando o próprio "pobre" - e não as condições que geravam a pobreza.

[...] a ciência e o poder podem se aliar e criar políticas preconceituosas, por vezes genocidas, 
que sob o discurso da diferença biológica separaram sociedades em classes sociais e confinaram os diferentes - considerados doentes por esses "cientistas" - em guetos, sanatórios prisões e campos de trabalho forçado. [...] A preocupação da comunidade médico-científica com os fenômenos ligados à população, tais como as epidemias, a miséria e o trabalho industrial, criaram novas estratégias de controle do corpo. Associadas às tecnologias já aplicadas em outros países do mundo, elas chegaram ao Brasil através da divulgação de associações e grupos eugenistas internacionais. (DIWAN, 2007, p. 13, p. 16 , grifo nosso)

Segundo os eugenistas, a seleção natural, descrita por Darwin, deveria atuar também nas questões sociais, e o ser humano estaria enfraquecendo a raça, ao praticar o assistencialismo, a reabilitação ou o desenvolvimento antinatural de procedimentos que impedissem a natureza de seguir seu próprio curso (DIWAN, 2007).

Para a elevação moral e o engrandecimento da
nação a eugenia propunha, basicamente, esti-
mular os nascimentos desejáveis (eugenia po-
sitiva) e desencorajar deliberadamente a união
e a procriação dos tarados e degenerados, con-
siderados nocivos à sociedade. Nessa categoria
estavam incluídas as pessoas tuberculosas, as
sifilíticas, as alcoolistas, as epiléticas, as aliena-
das e tantos outros indesejáveis (eugenia nega-
tiva). (BOARINI, 2003, p. 29)

Com o objetivo de formar uma raça superior, as ações propostas pelos eugenistas incluíam o impedimento da procriação daqueles considerados inferiores. Nos Estados Unidos, por exemplo, segundo Black (2003), os eugenistas estadunidenses, propunham intervenção direta na vida do povo, com ações - que foram postas em prática - sobre os chamados degenerados, como a esterilização compulsória, a proibição de casamentos, o descasamento (anulação de casamentos considerados inadequados eugenicamente) e o internamento em sanatórios. "Tudo isso foi tramado e produ- zido nos Estados Unidos, nos anos que antecederam a ascensão do Terceiro Reich na Alemanha" (BLACK, 2003, p. 21). Monteiro Lobato, em apoio às práticas eugênicas estadunidenses, afirmou: "Não pode haver país onde a eugenia esteja mais proclamada, estudada, praticada, 'livrada' [no sentido de publicada em livros] do que este [Estados Unidos]" [...]. (LOBATO, carta enviada a Renato Kehl em 8 de julho de 1929, apud NIGRI, 2011, p. 29)

No século XIX, o Brasil apresentava uma economia escravocrata e agrária e um “[...] quadro sanitário-educacional extremamente precário, tanto em zonas urbanas quanto em zonas rurais" (MAI, 2003, p. 45), que desencadearam um movimento pelo saneamento e pela saúde, em articulação com temas como clima, raça, natureza e busca pela construção de uma nova identidade nacional (MAl, 2003).

De acordo com Verzolla (2013), as ideias eugênicas tiveram aceitação de boa parte dos intelectuais brasileiros, porque, supostamente, vinham ao encontro dos interesses de defesa da nação contra o que lhe fosse improdutivo, anormal ou perturbador da ordem; com base em argumentos biológicos, instalaram-se no País a ideologia eugênica e as práticas higiênicas, em especial durante a gestão de Getúlio Vargas. Desse modo,

[...] a formação de um novo departamento nacional de saúde, em 1934, a ênfase no bem-estar infantil (ainda que ineficaz na prática), a restrição ao trabalho feminino e infantil (também ilusória) e a atenção dada à saúde das mães não podem ser entendidas sem referência à história da eugenia no país. (STEPAN, 2004, p. 374)

O apoio do presidente Getúlio Vargas ao programa eugênico pode ser constatado em mensagem apresentada por ele à Assembleia Constituinte em 1933:

Todas as grandes nações, assim merecidamente consideradas, atingiram nivel superior de 
progresso pela educação do povo. Refiro-me a educação, no significado amplo e social do vocábulo: física e moral, eugênica e cívica, industrial e agrícola, tendo por base a instrução primária de letras e a técnica e profissional. (INEP, 1987, p. 123, grifo nosso) ${ }^{1}$

A Constituição de 1934, a mesma que institucionalizou pela primeira vez no País a educação para todos², determina, dentre outras medidas, que estados e municípios deveriam "estimular a educação eugênica" (BRASIL, 1934, art. 138, b). Dignas de notas são também as medidas expressas nos art. 138, g; art. 145; art. 121, $\S 6$. o (BRASIL, 1934), com destaque para a instituição da educação escolar eugênica, a regulação dos casamentos e o controle da entrada de imigrantes. A Constituição de 1934 foi elaborada por uma Comissão do Itamaraty, formada por pessoas de diferentes posições ideológicas, dentre elas Oliveira Vianna (GODOY, 2017), que defendia a inferioridade racial dos negros e o determinismo da bagagem hereditária que a consolidava, acreditava na unidade e no caráter nacional do povo e argumentava a favor da intervenção do Estado para o embranquecimento da raça (BRESCIANI, 2010; ROCHA, 2016).

De acordo com Rocha (2016), a Constituição Federal de 1934 atuou até o golpe que instaurou o Estado Novo em 1937, quando foi outorgada por Getúlio Vargas a Constituição. Destaca-se o fato de que a comissão do Itamaraty baseou o artigo 138 no anteprojeto elaborado pela Comissão Brasileira de Eugenia ${ }^{3}$, formada

1 O livro no qual consta a presente citação de Getúlio Vargas teve sua escrita encomendada pelo Ministério da Educação à direção do Instituto Nacional de Estudos e Pesquisas Educacionais (INEP). A equipe designada coletou as fontes primárias e publicou na referida obra (INEP, 1987).

2 "[...]Ao mesmo tempo em que se discute a obrigatoriedade de ensino gratuito no país, a partir da criação de um Plano Nacional de Educação, defende-se o estímulo a 'Educação Eugênica', amparada por um discurso de exclusão do pobre, negro e imigrante" (ROCHA, 2016, p. 16).

3 “Em 1931, o incansável Kehl criou a Comissão Central Brasileira de Eugenia, cuja tarefa era promover a eugenia e fazer lobby pela legislação eugênica entre os por 11 membros e presidida por Renato Kehl (ROCHA, 2016).

Além disso, o ensino, na escola primária, de teorias e leis sobre hereditariedade era defendido como

[...] um valioso instrumento de prevenção de anormalidades, uma vez que transmitiria os princípios eugênicos, possibilitaria a valorização dos costumes saudáveis e moldaria os indivíduos com bons caracteres, para que buscassem matrimônio com indivíduos do mesmo nível, de maneira a proteger a prole. (SILVA, 2015, p. 32)

\section{perseverante ideal eugênico da eliminação da raça negra: um diálogo com Monteiro Lobato}

País de mestiços, onde branco não tem força para organizar uma Kux-Klan [sic], é país perdido para altos destinos. [...] Um dia se fará justiça ao Ku-Klux-Klan; tivéssemos aí uma defesa desta ordem, que mantém o negro em seu lugar, e estaríamos hoje livres da peste da imprensa carioca - mulatinho fazendo jogo do galego, e sempre demolidor porque a mestiçagem do negro destrói a capacidade construtiva (LOBATO, carta enviada a Arthur Neiva em 10 de abril de 1928, apud NIGRI, 2011, p. 26).

Entendida a Educação como um campo mais amplo, não restrito a conhecimentos escolares ou à educação formal, livros são meios pelos quais os sujeitos se educam, em diálogo silencioso com o autor, reafirmam diretrizes de vida, reveem conceitos assumidos como próprios, afetam-se para manter suas convicções ou confrontá-las, abrindo espaço para novas versões de si mesmo.

Partindo da premissa acima, a obra $O$ presidente negro, de Lobato, foi escolhida: era dirigida a adultos e tinha o propósito de demonstrar, valendo-se da ficção, a possibilidade de extermínio silencioso dos negros, pois

membros da Assembléia Constituinte" (STEPAN, 2004, p. 372-373). 
o próprio sujeito negro teria - supostamente - liberdade de comprar, ou não, o produto para alisar cabelos.

A obra faz também uma crítica à aparente política de tolerância racial do Brasil, ao mesmo tempo que enaltece as ações estadunidenses a partir das quais foi construída a utópica sociedade eugênica criada pela fantasia de Lobato. Diante da possibilidade de questionamento de ser 0 presidente negro "tão somente" uma obra de ficção, Diwan (2007) faz citação direta do trecho de uma epístola de Monteiro Lobato a Renato Kehl', na qual Lobato explicita suas motivações para escrevê-la:

[...] “Renato, Tu és o pai da eugenia no Brasil e a ti devia eu dedicar meu Choque, grito de guerra pró-eugenia. Vejo que errei não te pondo lá no frontispício, mas perdoais a este estropeado amigo. [...] Precisamos lançar, vulgarizar estas idéias. A humanidade precisa de uma coisa só: póda. É como a vinha. Lobato". (DIWAN, 2006, p. 106 , grifos nossos)

$\mathrm{Na}$ "Nota dos Editores" do livro O presidente negro, na segunda edição, de 1948, lê-se:

Lobato é sempre Lobato. [...]. Não se falsifica, não escreve para agradar $A$ ou $B$, e sim, unicamente, para dizer o que pensa - e com toda a clareza e crueza (p. VII).

$\mathrm{O}$ volume completa-se com "O Presidente $\mathrm{Ne}$ gro", uma fantasia visionadora do futuro, na qual a eugenia recebe todas as honras. A cena passa-se nos Estados Unidos, que então muito impressionavam Monteiro Lobato e para onde, em consequencia desse livro, passou a residir durante quase cinco anos... E temos que notar uma confissão depois que voltou: "Nada tenho a alterar no 'Choque das Raças'. A America que lá pintei está absolutamente de acordo com a America (Estados Unidos) que fui encontrar". (p. VIII, grifo nosso)

Em outro fragmento, também na Nota dos

4 A carta "[...] atualmente pertence a uma coleção de cartas de Lobato do Fundo Renato Kehl, do Centro de Documentação da Fundação Oswaldo Cruz no Rio de Janeiro" (DIWAN, 2007, p. 106).
Editores, o leitor se vê diante da afirmação de que, embora o livro possa parecer "brincadeira de talento", encerra um quadro do que realmente seria o mundo de amanhã, se fosse Lobato o reformador [...] 0 conserto do mundo pela eugenia [...]" (LOBATO, 1948, p. 125, grifos nossos).

De acordo com Diwan (2007, p. 101), o engajamento com a divulgação da eugenia e do sanitarismo marcou a produção literária de Monteiro Lobato:

O primeiro livro publicado por Monteiro Lobato foi uma coletânea de artigos publicados também em $O$ Estado de São Paulo, que trazia análises e críticas para o saneamento do Brasil. Intitulado Problema Vital (1918), teve patrocínio da Sociedade Eugênica de São Paulo (SESP) e da Liga Pró-Saneamento do Brasil (LPSB) e foi prefaciado por Renato Kehl (p. 101).

Em sua obra Urupês, a posição de Lobato torna-se explícita, o que faz de $O$ presidente negro uma espécie de ideal de sociedade defendida por ele:

Porque a Verdade núa manda dizer que entre as raças de variado matiz, formadoras da nacionalidade e metidas entre o estrangeiro recente e o aborigine de tabuinha em beiço, uma existe a vegetar de cocoras, incapaz de evolução, impenetrável ao progresso. Feia e sorna, nada a põe de pé (LOBATO, 1964, p. 279).

Pobre Jeca Tatu! Como é bonito no romance e feio na realidade! (LOBATO, 1964, p. 281).

Jeca Tatu é um Piraquara do Paraíba, maravilhoso epitome de carne onde se resumem todas as caracteristicas da especie (LOBATO, 1964, p. 280).

O fato mais importante de sua vida é sem duvida votar no governo (LOBATO, 1964, p. 285).

A modinha, como as demais manifestações de arte popular existentes no país, é obra do mulato, em cujas veias o sangue recente do europeu, rico de atavismos esteticos, borbulha d'envolta com o sangue selvagem, alegre e são do negro. 
O caboclo é soturno. (LOBATO, 1964, p. 291, grifos nossos)

Gonçalves (2011, [s.p.]) extrai um fragmento da carta de Lobato a seu amigo Godofredo Rangel, na qual confessa que a escrita "é um processo indireto de fazer eugenia, e os processos indiretos, no Brasil, 'work' muito mais eficientemente".

Lobato estava certo. Certíssimo. Até hoje, muitos dos que o leram não vêem nada de errado em seu processo de chamar negro de burro aqui, de fedorento ali, de macaco acolá, de urubu mais além. Porque os processos indiretos, ou seja, sem ódio, fazendo-se passar por gente boa e amiga das crianças e do Brasil, "work" muito bem. Lobato ficou frustradíssimo quando seu "processo" sem ódio, só na inteligência, não funcionou com os norte-americanos, quando ele tentou em vão encontrar editora que publicasse o que considerava ser sua obra prima em favor da eugenia e da eliminação, via esterilização, de todos os negros. Ele falava do livro "O presidente negro ou 0 choque das raças" [...]. (GONÇALVES, 2011, [s.p.])

Consideramos importante enfatizar que não temos como objetivo julgar Lobato, mas seguimos a recomendação de Boarini (2003, p. 14, grifo nosso), "partimos do princípio de que as idéias e preocupações dos cientistas de uma época não são emancipadas nas relações sociais até então existentes, estas traduzem questões determinadas historicamente, e como tais devem ser recuperadas" 5 .

5 “[...] ao abraçar a causa da eugenia, Lobato não teria sido apenas um homem de seu tempo? A resposta é: em termos. É certo que tal ideia tinha status de ciência na época, era bem aceita em determinados círculos intelectuais, e o termo estava tão na moda que aparecia até na poesia [...] A eugenia, no entanto, não era uma ideia majoritária, tanto que Lobato chamou Kehl de 'Quixote'. Um fato relevante a mostrar que havia muita gente consciente do absurdo da coisa foi o lançamento, em 1933, de Casa Grande e Senzala, o clássico de Gilberto Freyre - obra-prima que é resposta eloquente às bobagens defendidas por Kehl e pelo 'baiano germânico' Neiva. Em sua prosa irresistível, Freyre mostra o óbvio. o que influencia as carac-
De acordo com Bertucci (2013), a partir da segunda metade do século XIX até o início do $\mathrm{XX}$ as ideias nacionalistas foram amplamente debatidas por médicos, professores, advogados, dentre outros intelectuais que acabaram, em sua maioria, aderindo à explicação da diversidade humana a partir da desigualdade de raças e línguas, muito em voga nesse período.

[...] a mestiçagem da população fez muitos duvidarem que o país um dia estivesse entre as nações consideradas civilizadas. Com a difusão das teses evolucionistas e do darwinismo social (que apontava a primazia de leis biológicas como determinantes de civilidade), o branqueamento do país tornou-se questão crucial. (BERTUCCI, 2013, p. 219)

No Brasil, o branqueamento foi considerado a estratégia mais apropriada de extermínio. Dentre os seus defensores, alguns defendiam a miscigenação como meio, outros eram contra a mistura de raças. Cada um desses dois grupos defendia sua posição, conforme será exposto abaixo.

Os defensores da miscigenação viam o branqueamento como uma estratégia política e econômica tanto para assimilar uma raça recém-liberta da escravidão, que se submeteria a trabalhos a troco de baixo salário, como para construir uma identidade racial nacional branca.

Segundo Fulgêncio (2014, p. 203-204),

[...] a concepção do problema de escassez de mão de obra nos primeiros anos da República, bem como a solução encontrada para o mesmo na importação de trabalhadores de raça supostamente superior, com vistas, inclusive, na melhoria da qualidade étnica da população local por meio de um processo de miscigenação, decorreram do paradigma adotado pela inteligência nacional da época, que, com base

terísticas dos povos, se é que isso existe, é a cultura, como pregava o antropólogo alemão Franz Boas, e não a raça. O livro apresenta, também a mestiçagem que horrorizava os eugenistas como um valor positivo" (NIGRI, 2011, p. 32). 
na combinação de doutrinas raciais recebidas da Europa, criou a "teoria do branqueamento" especialmente para dar solução à realidade brasileira de uma população altamente miscigenada.

A extinção paulatina da raça negra viria da miscigenação.

Nesse debate de idéias, a miscigenação, um simples fenômeno biológico, recebeu uma missão política da maior importância, pois dela dependeria o processo de homogeneização biológica da qual dependeria a construção da identidade nacional brasileira. Foi nesse contexto que foi cunhada a ideologia do branqueamento, peça fundamental da ideologia racial brasileira. (MUNANGA, 2003, p. 10, grifos nossos)

Todavia, um grupo de famosos eugenistas brasileiros, com apoio de Monteiro Lobato, se opunha ao branqueamento a partir da miscigenação. Segundo Kehl (1923), seria necessário muito sêmen branco para se conseguir o branqueamento completo da raça negra e no final seria infrutífero, pois a raça superior (segundo ele, a branca) seria subjugada pelos traços inferiores da raça negra, no que se refere, principalmente, à inferioridade intelectual. "Sob o ponto de vista eugenico contra-indico toda e qualquer união de raça, isto é, entre individuos da raça branca com a negra, da branca com a selvagem, da branca com a amarella e assim por diante" (KEHL, 1923, p. 179).

A tese de Kehl (1923) se amparava, importante contextualizar, em argumentos organizados, mais notadamente, a partir do II Reinado no Brasil (1831-1889) até o início do século XX. Segundo Schwarcz (1993), esse período foi marcado pelo desenvolvimento de teorias raciais que indicavam a mestiçagem como motivo da falta de progresso do País. Expedições europeias e estadunidenses analisavam a fauna, a flora e o homem brasileiro e atribuíam à mestiçagem a causa do atraso do Brasil (pobreza, baixo índice de industrialização, doenças, etc.). A quase ausência de universidades brasileiras levava os filhos da elite a estudarem em instituições europeias ou americanas consideradas de prestígio. Retornavam ao Brasil influenciados pelas discussões raciais, conforme os ideários europeus ou americanos. Com a presença deles nas instituições brasileiras nas quais iniciavam seus trabalhos,

a discussão racial assumiu, naquele momento, um papel central, surgindo teses alternativas embora contemporâneas. Da frenologia dos museus etnográficos à leitura fiel dos germânicos da Escola de Recife, passando pela análise liberal da Escola de Direito paulista ou pela interpretação "católico-evolucionista" dos institutos, para se chegar ao modelo "eugênico" das faculdades de medicina, é possivel rever os diferentes trajetos que uma mesma teoria percorre [...] o fato é que esse modelo racial foi amplamente assumido nesse momento, constituindo-se em um argumento, quase consensual, para uma questão constantemente levantada e poucas vezes respondida: afinal, que país é esse? (SCHWARCZ, 1993, p. 25, p. 28, grifos no original)

A oposição de Lobato (1948) ao branqueamento pela miscigenação é defendida, também, no capítulo $X$, "Ceu e purgatório", de $O$ presidente negro. Nele, Jane, a protagonista principal, afirma que tal solução teria "estragado"

as duas raças, fundindo-as. 0 negro perdeu as suas admiraveis qualidades fisicas de selvagem e o branco sofre a inevitavel peora de carater, consequente a todos os cruzamentos entre raças dispares. Carater racial é uma cristalização que ás lentas se vai operando através dos seculos. 0 cruzamento perturba essa cristalização, liquefa-la, torna-a instavel. A nossa solução deu mau resultado [...] "O amor matou no Brasil a possibilidade de uma suprema expressão biologica. O odio criou na America [Estados Unidos] a gloria do eugenismo humano...". (LOBATO, 1948 , p. 206, p. 207, grifo nosso)

Todavia, no Brasil, a lógica de miscigenação acabou se impondo também por escolhas dos sujeitos das diferentes etnias existentes, 
implicados na noção de um país mestiço, "unidos", algumas vezes, pelos mesmos sofrimentos e desafios para sobreviver em um país em que o capitalismo se impunha com uma mão de obra barata e no qual o trabalho em situação de quase escravidão se mantinha ${ }^{6}$.

\section{Estratégias para o branqueamento: do}

\section{escamoteamento ao extermínio do negro}

Dizem que a mestiçagem liquefaz essa cristalização racial que é o caráter e dá uns produtos instáveis. Isso no moral - e no físico, que feiúra. Num desfile, à tarde, pela horrivel Rua Marechal Floriano, da gente que volta para os subúrbios, que perpassam todas as degenerescências, todas as formas e má-formas humanas - todas, menos a normal. Os negros da África, caçados a tiro e trazidos à força para a escravidão, vingaram-se do português de maneira mais terrivel - amulatando-o e liquefazendo-o, dando aquela coisa residual que vem dos subúrbios pela manhã e reflui para os subúrbios à tarde (LOBATO, carta a Godofredo Rangel incluída na primeira edição do livro A barca de Gleyre, em 1944, apud NIGRI, 2011, p. 33, grifo nosso).

Segundo definição do Dicionário Houaiss, a palavra "escamotear" vem do francês escamoter, significando "1. fazer com que (algo) desapareça sem que ninguém perceba [...] 2. furtar com destreza; surrupiar [...] 3. encobrir (algo) com rodeios ou subterfúgios" (HOUAISS, 2009, p. 796).

É, portanto, um desaparecimento gradual das coisas, de modo que não seja perceptivel. A ideia de fazer desaparecer a raça negra no ideário brasileiro está evidenciada na obra de Monteiro Lobato, em que a apoteose é a elimi-

6 Sobre a existência de trabalho escravo na atualidade, sugerimos:

PENA, Rodolfo F. Alves. Trabalho escravo no Brasil atual; Brasil Escola. Disponivel em: https://brasilescola.uol.com.br/brasil/trabalho-escravo-no-brasil-atual.htm. Acesso em: 30 maio de 2019. nação gradual dessa população e a expansão vigorosa da raça branca.

O branqueamento da população brasileira é algo que sempre esteve em voga no Brasil colônia. Hofbauer (2006) aponta que o casamento entre brancos e negros faria com que, em até quatro gerações de mestiçagem, a maior parte da população negra chegasse a ser branca. Para demonstrar seu argumento, apresenta uma Taboada das misturas, registrada em 1818, e que se apresenta da seguinte forma:

Para ficar branco: Branco com huma negra produz mulato - Metade branco, metade preto. Branco com huma mulata produz quartão - três quartos branco, e hum quarto negro. Branco com uma quartão produz outão - Sete oitavos branco, e hum oitavo negro. Branco com uma outona produz branco - Inteiramente branco. (GAIOSO, 1970, p. 119 apud HOFBAUER, 2006, p. 176)

Na obra de Lobato a "ciência" é convocada para articular estratégias de escamotear a negritude do negro (por branqueamento da pele e alisamento capilar), até o ponto em que, esterilizados sem se darem conta, os negros não perpetuassem a própria raça.

O segredo quanto á ação esterilizadora dos raios Omega conservava-se absoluto. [...]. Adotado esse maravilhoso processo, operou-se a esterilização dos homens pigmentados pelo unico meio talvez em condições de não acarretar para o país um desastre. 0 problema negro da America está pois resolvido da melhor forma para a raça superior, detentora do cétro supremo da realeza humana (LOBATO, 1948, p. 321, p. 322, p. 333).

Se, no início do século XIX, a possibilidade do branqueamento se daria pela mestiçagem, com argumentos científicos aliados a uma política trabalhista de precarização do trabalho negro, no escamoteamento, também alçado pela ciência, o branco se sobreporia ao negro, de tal modo que a sua eliminação não fosse apenas prevista, mas consentida pelo próprio negro. 
A identificação entre posição social elevada e cor branca era, aparentemente, ainda permeada por ou associada a um ideário religioso que relacionava "brancura" com "pureza divina". "Deus te faz balanco [branco]" teria sido um dos cumprimentos que negros e mestiços trocavam entre si. Segundo nos informam as anotações do pintor e desenhista francês Jean Baptiste Debret (n.p., II, p.497), que viveu no Brasil entre 1817 e 1831, esta fórmula teria sido uma adaptação da saudação religiosa "Deus te faça santo", com a qual os senhores costumavam responder aos seus subalternos quando estes últimos pediam "a benção, meu senhor". (HOFBAUER, 2006 , p. 175, grifos no original.)

O cumprimento "Deus te faz balanco" denota a vontade, o desejo de se ter uma cor diversa da que se tem, a fim de alcançar uma outra posição. $O$ branqueamento não se faria apenas pela mestiçagem prevista por fórmulas genéticas, mas por um processo de escamoteamento das características negroides, que levaria menos tempo que a previsão feita em a Taboada das misturas. As duas formas - a primeira em virtude da mistura das cores, a segunda por uma aproximação estética das características caucasianas - constituem meios de escamotear o negro, de modo que, de um jeito ou de outro, o desaparecimento gradual de uma raça se tornaria quase imperceptivel, pois contaria com a aceitação do negro.

Mas nem eliminando com os recursos da ciencia o caracteristico essencial da raça deixavam os negros de ser negros na America. Antes agradavam a sua situação social, porque os brancos, orgulhosos da pureza etnica e do privilegio da côr branca ingenita, não lhes podiam perdoar aquela camouflage da despigmentação. (LOBATO, 1948, p. 219)

Na população em geral, há pessoas que buscam fazer cirurgias bariátricas para perder peso, sem calcular seus riscos, porém, em muitos casos, mudanças de hábitos alimentares poderiam ser realizadas. Todavia, as pessoas querem efeitos e resultados imediatos.
$\mathrm{Na}$ busca do emagrecimento rápido, um outro exemplo de escamotear um sistema de vida que, em vários casos leva à obesidade, é o insistente apelo midiático de fast foods e alimentos pouco saudáveis do ponto de vista nutricional. Assim se descreve a situação de 2018 sobre as cirurgias bariátricas: "Para indicar a cirurgia é necessário, além de estar em uma faixa de peso ou de ter determinadas doenças, haver uma falência do tratamento clínico por 2 anos. Talvez 1\% desses 5 milhões [daqueles que buscam a cirurgia] seja de fato apto [...]" (GENOVESE, 2018, grifo nosso).

Alimenta-se, assim, uma cadeia produtiva que vai do lucro do produtor aos sistemas de saúde (do primário ao terciário) e às empresas farmacêuticas. Essa situação onera o sistema de saúde e se coloca no extremo oposto do projeto eugênico que advoga a opção racional pelo sujeito por não the ter sido oferecida, na escola, qualquer noção de educação alimentar. Ou, talvez, possamos hipotetizar que essa falta de educação nutricional seja também efeito de uma implícita política eugênica para eliminar um contingente populacional insustentável para os recursos atuais do planeta. As considerações aqui feitas mereceriam estudo e pesquisa à parte.

\section{Colorismo: a hierarquização da negritude e a localização social}

O homem só é humano na medida em que ele quer se impor a outro homem, a fim de ser reconhecido. Enquanto ele não é efetivamente reconhecido pelo outro, é este outro que permanece o tema da sua ação. É deste outro, do reconhecimento por este outro que depende seu valor e sua realidade humana [...] "A operação unilateral seria inútil, porque o que deve acontecer só pode se efetivar pela ação dos dois". (FANON, 2008, p. 180-181)

Segundo Neves (2015), o colorismo ${ }^{7}$ implica

7 "Termo colorismo ou pigmentocracia foi desenvolvido por Alice Walker, no ensaio 'If the Present Looks 
que alguns privilégios são dados às pessoas negras, conforme a intensidade da cor de sua pele (se mais clara ou mais escura). Isso geraria na branquitude um lugar de aceitação para essas pessoas, mas nunca o seu reconhecimento como iguais. Dito de outro modo, à pessoa negra de pele mais clara pode ser franqueada a participação em determinados grupos ou associações, desde que não almeje chegar ao mesmo lugar em que está a pessoa branca. 0 problema é que pessoas de pele mais clara podem não perceber quando são vítimas de preconceito racial (DJOKIC, 2015).

Entretanto, não são as modificações externas que determinam que haverá, em certa medida, a alienação dos traços culturais e étnicos de um indivíduo, mas são os padrões estabelecidos, pautados em um ideal de beleza eurocêntrico, que os colocam à margem, que dão vazão ao desejo de obter outros traços que possibilitem maior "acesso" a outros locais sociais e de pertencimento.

Para exemplificar, o clareamento artificial da pele e o alisamento dos cabelos, no romance de Lobato, não fizeram os negros brancos, porque o nariz deles se mantinha alargado e os cabelos crespos apresentavam uma cor de pele esbranquiçada, como efeito do clareamento artificial da pele: sua cor era, para os políticos brancos, a cor de "barata descascada" (LOBATO, 1948, p. 218). Portanto, fenotípica e geneticamente seriam negros e, como tais, não teriam os mesmos direitos e reconhecimentos dos brancos.

A manutenção de uma estética que valoriza os traços étnicos não necessariamente implica a apropriação de uma herança cultural e a consciência do seu significado por um sujei-

Like the Past, What Does the Future Look Like?', imprimido no livro 'In Search of Our Mothers' Garden' em 1982. Segundo o Oxford Dictionaries nomeia 'um sistema de distinção social ou de classe baseado na cor da pele; uma sociedade baseada em tal sistema; o grupo dominante em tal sociedade' " (FRANCISCO, 2018, p.102). to que viva no espaço geográfico em que uma dada cultura se organizou e se constitui (SILVA, 2014). Com isso, existe uma dificuldade do sujeito para reconhecer sua própria identidade étnica. Essa dificuldade em situar uma etnia, e ao mesmo tempo uma cor, é uma questão digna de destaque. Segundo Schwarcz (2013), quando da realização do Censo do IBGE de 1976, quando as pessoas podiam declarar de qual cor eram, houve 136 respostas diferentes. Essas 136 definições dadas pelos entrevistados poderiam ser tema de um outro estudo. No entanto, o que se pretende aqui é demonstrar o quanto a definição da própria cor é complexa para uma população de sujeitos no Brasil, ainda mais quando se autodeclarar de uma determinada cor - ser negro ou preto pode trazer mais - ou menos - beneficios. Dito de outro modo, mantém-se o receio de que, ao assumir a própria cor (preta), se agregue a discriminação, com atitudes racistas veladas ou não ${ }^{8}$.

\section{Racismo e a palavra que mata: uma história sem fim (ainda)}

Por vezes este maniqueísmo vai até ao fim da lógica e desumaniza o colonizado. A rigor, animaliza-o. E, de fato e fato, a linguagem do colono, quando fala do colonizado, é uma linguagem zoológica. Faz alusão aos movimentos reptis do amarelo, às emanações da cidade indígena, às hordas, ao fedor, à população, ao balbucio, à gesticulação. (Fanon, 1968, p. 31)

No final do diálogo entre os eugenistas e a obra de Lobato (1948), conclui-se que só cabe-

8 Interessante é que fenômeno similar pode ocorrer entre surdos implantados, que sofrem ou sofreram preconceito pelos surdos não implantados. Alguns deles têm certa dificuldade de se autodeclarar surdos ou deficientes auditivos. Continuam sendo surdos do ponto de vista nosográfico, mas podem parecer ouvintes. A dúvida identitária aí se coloca, posto que não é apenas a língua a única medida que faz um sujeito se ver ou se identificar com um grupo social, a partir do qual possa ter a ilusão de estar entre iguais, ou em "casa". 
ria, na ficção (ficção?), a eliminação consentida do negro a favor da "superioridade" da raça branca. Perversa, mas esperada no rastro da premissa exposta em frase anterior, foi a forma encontrada pela Convenção da Raça Branca para que os negros fossem, gradualmente, extintos nos Estados Unidos da América. Nessa convenção há a decisão de que algo fosse feito para que o presidente negro, então eleito, não assumisse o cargo.

O racismo e o ódio entre grupos humanos sempre existiram; entretanto, foram necessárias centenas de anos para que o pensamento científico desenvolvesse, de modo escamoteado, ações de exclusão ou eliminação daquele considerado inferior ou não espelho de si (BLACK, 2003; SOUZA; GALLO, 2002). E assim afirma Foucault (2010, p. 52):

[...] o que vemos como polaridade, como fratura binária na sociedade, não é o enfrentamento de duas raças exteriores uma à outra; é o desdobramento de uma única e mesma raça em uma super-raça e uma sub-raça. [...] esse discurso da luta das raças [...] vai ser recentralizado e tornar-se justamente o discurso do poder, de um poder centralizado, centralizado e centralizador; o discurso de um combate que deve ser travado não entre duas raças, mas a partir de uma raça considerada como sendo a verdadeira e a única, aquela que detém o poder e aquela é titular da norma, contra aqueles que estão fora dessa norma, contra aqueles que constituem outros tantos perigos para o patrimônio biológico. E vamos ver, nesse momento, todos os discursos biológico-racista sobre a degenerescência, mas também todas as instituições que, no interior do corpo social, vão fazer o discurso da luta das raças funcionar como princípio de eliminação, de segregação e, finalmente, de normalização da sociedade [...].

Fato que fica sem explicação, no livro de Lobato, é a morte do então presidente eleito, Jim Roy, após a notícia de que o produto para alisamento dos cabelos contribuía para a esterilização da população negra. Em nenhum mo- mento do livro há a menção de que o produto usado por ele tinha um potencial mais danoso que o usado por outras pessoas.

É na conversa com o presidente em exercício que a morte está posta para Jim Roy, é naquilo que é explicitado na conversa que se coloca todo o desejo de aniquilação de toda a população negra, não de modo abrupto, mas paulatinamente, de modo que essa eliminação, como afirmado acima, seja escamoteada. Pouco a pouco ela se dará, mas começa com a impossibilidade de uma representação efetiva da população negra, que tem o seu líder morto antes mesmo de sua posse.

Adentramos, portanto, no campo do simbólico, já que Kerlog leva a Jim Roy “a palavra que mata". A linguagem e a interpretação da linguagem, seja ela falada, gestual ou escrita, estão imbuídas de simbolismos, pois é a interpretação do outro que dá sentido à linguagem e constitui o sujeito que dela faz parte como elo integrante - sendo falado e se fazendo falar. E o outro, o Próximo, não é o semelhante, se põe como diferença a ser enfrentada.

[...] o Próximo é originariamente (como Freud suspeitou há muito tempo) uma coisa, um intruso traumático, alguém cujo modo de vida diferente (ou antes, cujo modo jouinsssance diferente, materializado em suas práticas e ritos sociais) nos perturba, abala o equilíbrio dos trilhos sobre os quais nossa vida corre, quando chega perto demais, esse fato pode também dar origem a uma reação agressiva visando afastar o intruso incômodo. Nos termos de Peter Sloterdijk: "Mais comunicação significa em um primeiro momento, acima de tudo, mais conflito". (ZIZEK, 2014, p. 58)

Fazendo um paralelo a tal cenário, temos a comunicação, em $O$ presidente negro, do momento em que Jim Roy, ao invés de apoiar um dos candidatos brancos, lança-se como candidato à presidência. A informação é dada e imediatamente as pessoas votam nele. Como a maior parte dos eleitores são negros, o candi- 
dato logo se elege, atraindo para si a fúria dos demais candidatos.

É esse conflito, que se estabelece pela proximidade, que é instalado no momento em que o candidato negro se elege. Este passa a ser o "intruso incômodo", como apontado no trecho acima, e todo incômodo precisa ser eliminado de alguma forma. É na violência da fala que essa eliminação/morte se estabelece. A fala materializa, em algum sentido, o desejo que está conscientemente instalado a respeito daquilo que é o diferente.

Temos, portanto, a fala do presidente representante dos brancos e a não escuta daquilo que os negros querem, daquilo que desejam, ou seja, um espaço para viver e ser o que são: negros. E ponto.

\section{Referências}

BERTUCCI, Liane Maria. Sanear a raça pela educação - teses da Faculdade de Medicina e Cirurgia de São Paulo, início dos anos 1920. In: MOTA, André; MARINHO, Maria Gabriela S. M. C. (Orgs.). Eugenia e história: ciência, educação e regionalidades. São Paulo: CD.G Casa de Soluções Editoras, 2013. p. 219238. (Coleção Medicina, Saúde e História, v. 4). Disponivel em: https://www.academia.edu/5434282/ Eugenia_e_Hist\%C3\%B3ria_-_Ci\%C3\%AAncia_Educa\%C3\%A7\%C3\%A30_e_Regionalidades. Acesso em: 23 jul. 2019.

BLACK, Edwin. Guerra contra os fracos: a eugenia e a campanha dos Estados Unidos para criar uma raça dominante. Tradução de Tuca Magalhães. São Paulo: A Girafa, 2003.

BOARINI, Maria Lúcia. Apresentação. In: BOARINI, Maria Lúcia (Org.) Higiene e raça como projetos: higienismo e eugenismo no Brasil. Maringá: Eduem, 2003. p.11-18.

Higienismo, eugenia e a naturalização do social. In: (Org.) Higiene e raça como pro-

jetos: higienismo e eugenismo no Brasil. Maringá: Eduem, 2003. p. 19-43.

BRASIL. Constituição da República dos Estados Uni- dos do Brasil (de 16 de julho de 1934). Diário Oficial da União de 16 de julho de 1934. Disponivel em: http://www.planalto.gov.br/ccivil_03/Constituicao/ Constituicao34.htm. Acesso em: 16 jan. 2019.

BRESCIANI, Maria Stella. Projetos políticos nas interpretações do Brasil na primeira metade do século XX. Revista de História - USP, São Paulo, Ed. Especial, p.187-215, jun. 2010. Disponivel em: http://www.revistas.usp.br/revhistoria/article/view/19144/21207. Acesso em: 23 jul. 2019.

CARVALHO, Marco Antônio. Taxa de homicídios de negros é mais do que o dobro da de brancos no País. 0 Estado de S. Paulo, 5 jun. 2018. Disponivel em: https://sao-paulo.estadao.com.br/noticias/ geral,taxa-de-homicidios-de-negros-e-mais-doque-o-dobro-da-de-brancos-no-pais,70002337809. Acesso em: 24 jul. 2018.

DIWAN, Pietra. Raça pura: uma história da eugenia no Brasil e no mundo. São Paulo: Contexto, 2007.

DJOKIC, Aline. Colorismo: o que é, como funciona. Geledés. Sessão Mulher. 26 fev. 2015, n.p. Disponivel em: https://www.geledes.org.br/colorismo-o-que -e-como-funciona/. fev. 2015. Acesso em: 05 maio 2018.

FANON, Frantz. Os condenados da terra. Tradução de José Laurêncio de Melo. Rio de Janeiro: Civilização Brasileira, 1968. (Coleção Perspectivas do Homem, v. 42. Série Política).

Pele negra, máscaras brancas. Tradução de Renato da Silveira. Salvador: EdUfba, 2008.

FÓRUM BRASILEIRO DE SEGURANÇA PÚBLICA. Atlas da Violência 2019. Organizadores: Instituto de Pesquisa Econômica Aplicada. Fórum Brasileiro de Segurança Pública. Brasília: Rio de Janeiro: São Paulo: Instituto de Pesquisa Econômica Aplicada; Fórum Brasileiro de Segurança Pública, 2019.

FOUCAULT, Michel. A ordem do discurso. 20. ed. São Paulo: Loyola, 2010.

FRANCISCO. Mônica da Silva. Discursos sobre colorismo: educação étnico-racial na contemporaneidade. Ensaios Filosóficos, v. XVIII, p. 97-109, dez. 2018. Disponivel em: http://www.ensaiosfilosoficos.com. 
br/Artigos/Artig018/07_FRANCISCO_Ensaios_Filosoficos_volume_XVIII.pdf. Acesso em: 20 jun. 2019.

FREYRE, G. Casa Grande \& Senzala: formação da família brasileira sob o regime da economia patriarcal. São Paulo: Global, 2003.

FULGÊNCIO, Rafael Figueiredo. O paradigma racista da política de imigração brasileira e os debates sobre a "Questão Chinesa" nos primeiros anos da República. Revista de Informação Legislativa, ano 51, n. 202, p. 203-221, abr./jun. 2014. Disponível em: http://www2.senado.leg.br/bdsf/handle/ id/503045. Acesso em: 23 jul. 2019.

G1 CAMPINAS E REGIÃO (editorial). PM de Campinas deixa vazar ordem para priorizar abordagens em negros. G1 Campinas e Região, Campinas, 23 jan. 2013 , n.p. Disponivel em: http://g1.globo.com/sp/ campinas-regiao/noticia/2013/01/pm-de-campinas-deixa-vazar-ordem-para-priorizar-abordagens -em-negros.html. Acesso em: 15 jan. 2019.

GENOVESE, Bruno. Cirurgia bariátrica cresce $47 \%$ em cinco anos no Brasil. [Entrevista concedida a] Gabriel Alves. Folha de São Paulo, São Paulo, 09 jul. 2018. Disponivel em: https://www1.folha.uol.com. br/equilibrioesaude/2018/07/cirurgia-bariatricacresce-47-em-cinco-anos-no-brasil.shtml. Acesso em: 3 jul. 2019.

GODOY, Arnaldo Sampaio de Moraes. A constituição de 1934 no contexto da história do constitucionalismo brasileiro. Revista Jurídica Cesumar, jan./abr. 2017, v. 17, n. 1, p. 181-211. Disponivel em: http://dx. doi.org/10.17765/2176-9184.2017v17n1p181-21. Acesso em: 23 jul. 2019.

GONÇALVES, Ana Maria. Carta Aberta ao Ziraldo. Atabaque Blog (Geledés), 21 fev. 2011. Artigos e Reflexões, n.p., 2011. Disponivel em: https:/ / www.geledes.org.br/carta-aberta-ao-ziraldo-por-ana-mariagoncalves-2/. Acesso em: 27 jul. 2019.

HOFBAUER, Andreas. Uma história de branqueamento ou o negro em questão. São Paulo: Editora UNESP, 2006.

HOUAISS, Antonio; VILLAR, Mauro de Salles. Dicionário Houaiss da língua portuguesa. Rio de Janeiro: Objetiva, 2009. p. 796.
INEP - Instituto Nacional de Estudos e Pesquisas Educacionais. A educação nas mensagens presidenciais (1890-1986). v. 1. Brasília: MEC/INEP, 1987.

KEHL, Renato. A cura da fealdade: eugenia e medicina social. São Paulo: Monteiro Lobato \& Co. Editores, 1923.

LANG, Marina. Laudo aponta mais de 200 tiros em ação militar que matou músico e catador. UOL, Rio de Janeiro, 09 maio 2019. Sessão Cotidiano, n.p. Disponivel em: https://noticias.uol.com.br/cotidiano/ ultimas-noticias/2019/05/09/laudo-aponta-maisde-200-tiros-em-acao-militar-que-matou-musico -e-catador.htm. Acesso em: 21 maio 2019.

LOBATO, Monteiro. O Presidente Negro ou O choque das raças (Romance americano do ano 2228). In:

A Onda Verde e o Presidente Negro. São

Paulo: Brasiliense, 1948. 2. ed. Obras Completas de Monteiro Lobato, 1a série. v. 5. p. 123-330.

LOBATO, Monteiro. Urupês. 13. ed. São Paulo: Brasiliense, 1964. 1a série. v. 1.

MAl, Lilian Denise. Difusão dos ideários higienistas e eugenistas no Brasil. In: BOARINI, Maria Lúcia (Org.). Higiene e raça como projetos: higienismo e eugenismo no Brasil. Maringá: Eduem, 2003.

MENEZES, César. Negros representam 71\% das vítimas de homicídios no país, diz levantamento. Jornal Nacional, São Paulo, 18 nov. 2017, n.p. Disponivel em: https://g1.globo.com/sp/sao-paulo/noticia/ negros-representam-71-das-vitimas-de-homicidios-no-pais-diz-levantamento.ghtml. Acesso em: 22 jul. 2019.

MUNANGA, Kabengele. Prefácio. In: CARONE, Iray; BENTO, Maria Aparecida Silva (Orgs.). Psicologia Social do Racismo: estudos sobre branquitude e branqueamento no Brasil. 2. ed. Petrópolis: Vozes, 2003. p. 9-11.

NASCIMENTO, Abdias. 0 genocídio do negro brasileiro. Rio de Janeiro: Paz e Terra, 1978.

NEVES, Consuelo. Colorismo: quem decide? Disponivel em: http://blogueirasnegras.org/02/03/colorismo-quem-decide. 3 de fevereiro de 2015. Acesso em: 05 maio 2018. 
NIGRI, André. Monteiro Lobato e o racismo: cartas inéditas reforçam que o autor do "Sítio do Picapau Amarelo" se entusiasmou com a eugenia - pretensa ciência que ajudou a embasar o nazismo e o holocausto. Revista Bravo!, São Paulo, ano 13, n. 165, maio 2011, Sessão: Livros, p. 24-33.

ROCHA, Simone. Política de branqueamento na educação brasileira: a eugenia na Era Vargas. In: XI COLUBHE - CONGRESSO LUSO BRASILEIRO DE HISTÓRIA DA EDUCAÇÃO, 11., 2016, Porto, Portugal. Anais... Comunicações individuais. Eixo Políticas e práticas educativas. p. 2-17. Disponivel em: http://web3.letras.up.pt/colubhe/actas/eixo3.pdf. Acesso em: 19 jul. 2019.

SCHWARCZ, Lilia Moritz. 0 espetáculo das raças: cientistas, instituições e questão racial no Brasil 1870-1930. São Paulo: Companhia das Letras, 1993.

Racismo no Brasil. São Paulo: Publifolha, 2013.

SILVA, Helder Kuiawinski da. A cultura afro como norteadora da cultura brasileira. Perspectiva, Erechim, v. 38, n.144, p. 25-35, dez. 2014. Disponivel em: http://www.uricer.edu.br/site/pdfs/perspectiva/144_449.pdf. Acesso em: 30 maio 2019.

SILVA, Morena Dolores Patriota da. Marcas eugênicas na educação de surdos no século XIX. 2015. 197 f. Dissertação (Mestrado em Educação) - Universidade Estadual de Campinas, Campinas, 2015. Disponivel em: http://repositorio.unicamp.br/bitstream/ REPOSIP/305014/1/Silva_MorenaDoloresPatriotada_M.pdf. Acesso em: 10 jun. 2018.
STEPAN, Nancy Leys.Eugenia no Brasil, 1917-1940. In: HOCHMAN, G., and ARMUS, D. (Orgs.). Cuidar, controlar, curar: ensaios históricos sobre saúde e doença na América Latina e Caribe [online]. Rio de Janeiro: Editora FIOCRUZ, 2004. p. 330-391. (História e Saúde collection). Disponivel em: http://books.scielo.org/ id/7bzx4. Acesso em: 24 jul. 2019.

SOUZA, Regina Maria de; GALLO, Silvio. Por que matamos o barbeiro? Reflexões preliminares sobre a paradoxal exclusão do outro. Educação \& Sociedade, Campinas, UNICAMP, ano XXIII, n. 79, p. 39-63, ago. 2002. Disponivel em: www.scielo.br/pdf/es/ v23n79/10848.pdf. Acesso em: 23 jul. 2019.

SOUZA, Renata. Quantos mais vão precisar morrer para essa guerra acabar? El País. Rio de Janeiro. 17 maio 2018. Sessão: Opinião. n.p. Disponivel em: https:/ / brasil.elpais.com/brasil/2018/05/16/politica/1526427937_505226.html. Acesso em: 11 fev. 2019.

VERZOLLA, Beatriz Lopes Porto. As imagens da doença e da degeneração racial nos livros didáticos (1920-1930). In: MOTA, André; MARINHO, Maria Gabriela Silva Martins da Cunha (Orgs.). Eugenia e história: ciência, educação e regionalidades. São Paulo: USP, Faculdade de Medicina: UFABC, Universidade Federal do ABC: CD.G Case de Soluções e Editora, 2013.

ZIZEK, Slavoj. Violências: seis reflexões laterais. Tradução Miguel Serras Pereira. 1. ed. São Paulo: Boitempo, 2014.

Recebido em: 27.08.2019

Aprovado em: 20.03.2020

Regina Maria de Souza é Doutora em Linguística pela Universidade Estadual de Campinas. Mestra em Psicologia pela Pontificia Universidade Católica de Campinas. Professora livre docente na Universidade Estadual de Campinas - Faculdade de Educação. E-mail: reginalaghi@hotmail.com

Morena Dolores Patriota da Silva é doutoranda no Programa de Pós-Graduação da Faculdade de Educação da Universidade Estadual de Campinas (UNICAMP). Mestra em Educação pela Universidade Estadual de Campinas. Grupo de Pesquisa: DiS - Diferenças e Subjetividades em Educação (UNICAMP). Atualmente é Pedagoga do Instituto Federal do Paraná, Campus Londrina. E-mail: morenadolores@gmail.com

Cristiane Maria da Silva é mestranda em Educação no Programa de Pós-graduaçãoem educação da UNICAMP. Grupo de Pesquisa: DiS - Diferenças e Subjetividades em Educação (UNICAMP). Graduada em Psicologia pela Universidade Cruzeiro do Sul atuando em Psicologia Social no município de Sumaré (Secretaria Municipal de Desenvolvimento e Inclusão Social de Sumaré (SP). E-mail: cristianemaria.silva2@gmail.com 